\title{
Lack of Prosodic Focus in Chongqing Dialect and Possible Historical Sources
}

\author{
Zixin $\operatorname{Qin}^{1}, Y i X u^{2}$ \\ ${ }^{1}$ Department of Linguistics, University College, UK \\ ${ }^{2}$ Department of Speech, Hearing and Phonetic Sciences, University College London, UK \\ zixin.qin.18@ucl.ac.uk, yi.xu@ucl.ac.uk
}

\begin{abstract}
This study investigates Chongqing Dialect, a language largely used in Southwest China which is mutually intelligible to Beijing Mandarin speakers. Phonetic variations triggered by focus in Chongqing Dialect, especially in the form of post-focus compression (PFC), are investigated in terms of max $\mathrm{F}_{0}$, mean $\mathrm{F}_{0}$, duration and intensity. A follow-up perception test is also conducted. The production experiment shows that there are no significant changes from no focus condition to focus condition in the factors analysed, and no PFC is observed in Chongqing Dialect. The perception test shows a rather low identification rate at around $40 \%$. The results of this study support the hypothesis that there is a typological divide within the Chinese languages, and the reason is explored by an analysis of the historical roots of Chongqing Dialect. As a representative of Southwest Mandarin, the lack of PFC in Chongqing Dialect suggests that many other Southwest Mandarin dialects also may not have PFC.

Index Terms: Chongqing Dialect, prosodic focus, post-focus compression, focus perception
\end{abstract}

\section{Introduction}

In many languages focused constituents have been found to be phonetically realized by variations of fundamental frequency $\left(\mathrm{F}_{0}\right)$, duration and intensity. In non-tone languages, there is evidence that $F_{0}$ variation is a major manifestation of prosodic focus [1, 2]. In some tone languages, such as Beijing Mandarin, although $\mathrm{F}_{0}$ variations are already used to distinguish words, $\mathrm{F}_{0}$ contour modifications are also applied to mark focus [3]. In particular, compression of pitch range is observed in post-focus regions in an utterance, a phenomenon known as "post-focus compression" (PFC) [4]. PFC has been reported in many languages such as Swedish, Dutch and English [5, 6, 7]. However, it is not universal. The presence of PFC is found in the majority of Indo-European, Altaic and Uralic languages, but varies across languages and dialects in Sino-Tibetan language family. Beijing Mandarin [3], Nanchang Dialect [8] and Lanyin Mandarin [9] all show clear patterns of PFC, while Taiwanese [4], Cantonese [10], Li [8], Yi [8] and Deang [8] all lack PFC. Southwest Mandarin, a well-known dialect variety of Mandarin, has received increasing attention in latest research. A recent study has reported that Dali Mandarin, a variety of Southwest Mandarin in China, does not use pitch variation to signal focus [11], which suggests that there is no PFC in that dialect. Chongqing Dialect, the target language of the present study, is another major variety of Southwest Mandarin. So far there is no mentioning of whether PFC is present in Chongqing Dialect.

The aim of the present study is therefore to examine the production and perception of prosodic focus in Chongqing
Dialect, with the major objective to determine the presence of PFC as a marker of focus in the dialect. Given the reported lack of focus-related pitch variation in Dali Mandarin [11], it is predicted that PFC is absent in Chongqing dialect.

\section{Methods}

\subsection{Production experiment}

\subsubsection{Stimuli}

The stimuli consisted of two target sentences, as shown in Table 1. During recording, each sentence was illustrated by a picture depicting the scenario in the corresponding sentence. In each sentence, there were three words. The only difference between the two sentences was that the short one had five syllables while the long one had seven syllables. Table 2 listed the precursor questions to elicit target sentences in four focus conditions: no focus, initial focus (word 1), medial focus (word 2), and final focus (word 3). Each of them concentrated on one aspect shown in the picture. The target sentences and the precursor questions were randomized by a JavaScript which also repeated them three times. Thus, there were 2 sentences $\times 4$ foci $\times 3$ repetitions $=24$ sentences for each speaker.

Table 1: Target sentences in Chongqing Dialect.

\begin{tabular}{cccc}
\hline & Word 1 & Word 2 & Word 3 \\
\hline $\begin{array}{c}\text { Gloss \& } \\
\text { Transcription }\end{array}$ & $\begin{array}{c}\text { [ma214 ma55] } \\
\text { 'mother' }\end{array}$ & $\begin{array}{c}\text { [mo21] } \\
\text { 'stroke' }\end{array}$ & $\begin{array}{c}\text { [mau214 ə55] } \\
\text { 'kitty' }\end{array}$ \\
\hline $\begin{array}{c}\text { Gloss \& } \\
\text { Transcription }\end{array}$ & $\begin{array}{c}\text { [zan214 won55] } \\
\text { 'Zhangwen' }\end{array}$ & $\begin{array}{c}\text { [pay55 ciau214 } \\
\text { inə55] } \\
\text { 'Xiaoying' }\end{array}$ & $\begin{array}{c}\text { [pan55 su214] } \\
\text { 'move books' }\end{array}$ \\
\hline
\end{tabular}

Table 2: Precursor questions for eliciting the target sentences with different focus conditions.

\begin{tabular}{|c|c|c|}
\hline Focus & Precursor Question & Transcription \\
\hline None & $\begin{array}{l}\text { What do you see in } \\
\text { the picture? }\end{array}$ & $\begin{array}{c}{\left[\text { ni55 } \mathrm{ts}^{\mathrm{h}} \text { on } 42 \mathrm{t}^{\mathrm{h}} \mathrm{u} 42 \text { zon } 55\right.} \\
\mathrm{k}^{\mathrm{h}} \text { an42 tau55 lə55 sa21 zi21] }\end{array}$ \\
\hline \multirow{2}{*}{ Initial } & $\begin{array}{l}\text { Who is stroking the } \\
\text { kitty? }\end{array}$ & $\begin{array}{c}\text { [na55 kə42 zai21 mo21 } \\
\text { mau214 ə42] }\end{array}$ \\
\hline & $\begin{array}{l}\text { Who helps Xiaoying } \\
\text { move books? }\end{array}$ & $\begin{array}{l}\text { [na55 kə42 pan55 ciau42 } \\
\text { inə42 pan42 su42] }\end{array}$ \\
\hline \multirow{2}{*}{ Medial } & $\begin{array}{l}\text { What is Mom doing } \\
\text { to the kitty? }\end{array}$ & $\begin{array}{l}{[\mathrm{ma} 214 \text { ma55 zai42 tuei42 }} \\
\text { mau214 } 42 \text { zuo21 sa21 zi21] }\end{array}$ \\
\hline & $\begin{array}{l}\text { Who does Zhangwen } \\
\text { help move books? }\end{array}$ & $\begin{array}{l}\text { [zay214 wən55 pan55 na214 } \\
\text { gə42 pan21 su21] }\end{array}$ \\
\hline \multirow{2}{*}{ Final } & $\begin{array}{l}\text { What is Mom } \\
\text { stroking? }\end{array}$ & $\begin{array}{c}\text { [ma214 ma55 zai42 mo55 } \\
\text { sa21 zi21] }\end{array}$ \\
\hline & $\begin{array}{c}\text { What does Zhangwen } \\
\text { help Xiaoying do? }\end{array}$ & $\begin{array}{l}\text { [zay214 wən55 pay55 ciau214 } \\
\text { inə55 zuo21 sa21 zi21] }\end{array}$ \\
\hline
\end{tabular}




\subsubsection{Recording procedures and data extraction}

Nine native Chongqing Dialect speakers participated in the experiment, including 5 females and 4 males, aged from 48-68. All the recordings took place in a quiet room, and every speaker recorded both the short and long sentences. Their utterances were recorded by the internal microphone of a SONY ICD PX333 Digital Voice Recorder. One set of randomized precursor questions and target sentences were shown at a time on a computer screen, and speakers were asked to read aloud both the precursor questions and target sentences. As demonstrated in many previous studies, this procedure could effectively elicit correct focus types in target sentences [3, 4, 12]. All the speakers received substantial practice trials to get familiar with the experiment procedures. There was a threesecond interval between trials.

Data extraction and marking was done using ProsodyPro [13], a script operating on Praat [14] for large-scale prosody analysis. After manual segmentation and rectification, it saves ensemble files, including the raw data of max $F_{0}$, mean $F_{0}$, intensity, and duration, and other files for analysis.

\subsubsection{Data analysis}

Figure 1 shows mean time-normalized $F_{0}$ contours of both target sentences in four focus conditions produced by 9 speakers. Each curve displays the average of $9 \times 3=27$ repetitions of Chongqing Dialect sentences. A clear trend of increase of average $\mathrm{F}_{0}$ in on-focus region is only observed in initial focus in the short sentence. Aside from this increase, there is very little difference across the four focus conditions. Overall, $\mathrm{F}_{0}$ contours show similar patterns for all the focus conditions in each sentence. To confirm the above observations, a series of separate t-tests are performed. The independent variable is focus condition (neutral, initial, medial, and final), and the dependent variable is mean $\mathrm{F}_{0}$. The results are shown in Table 3. A significant increase is only observed in on-focus region in initial focus condition in short sentence $[\mathrm{t}(8)=-3.068$, $p=.015]$.

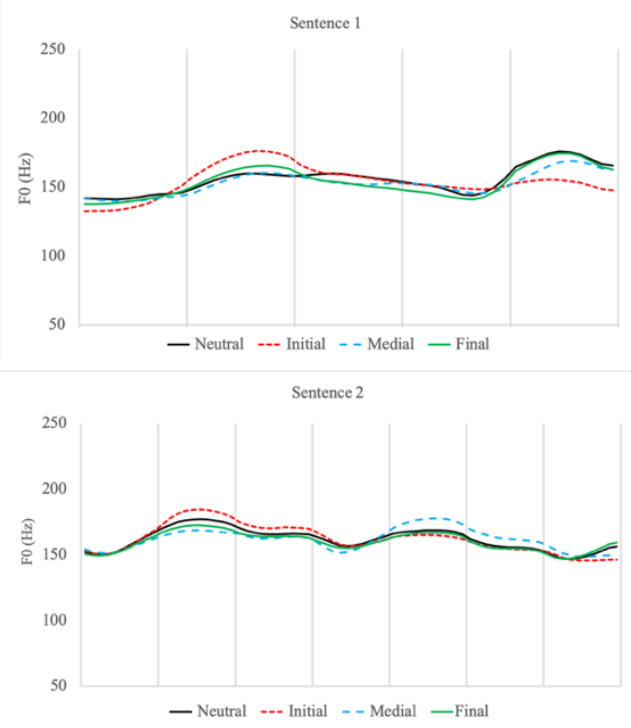

Figure 1: Mean time-normalized $F_{0}$ contours of two target sentences by 9 speakers. Each curve displays the average of 27 repetitions of Chongqing Dialect sentences. Vertical lines represent the syllable boundaries.
Table 3: Results of t-test. Degrees of freedom are 8. P values less than .05 are in boldface.

\begin{tabular}{|c|c|c|c|c|}
\hline \multirow{2}{*}{ Sentence } & \multirow{2}{*}{$\begin{array}{r}\begin{array}{c}\text { Focus } \\
\text { Region }\end{array} \\
\text { Condition }\end{array}$} & Pre-focus & On-focus & Post-focus \\
\hline & & $p$ & $p$ & $p$ \\
\hline \multirow{3}{*}{ Short } & Initial & & $-3.068 ; .015$ & $1.108 ; .300$ \\
\hline & Medial & $.914 ; .388$ & $1.533 ; .164$ & $1.323 ; .222$ \\
\hline & Final & $.405 ; .696$ & $.799 ; .447$ & \\
\hline \multirow{3}{*}{ Long } & Initial & & $-1.425 ; .192$ & $.554 ; .595$ \\
\hline & Medial & $2.333 ; .058$ & $.001 ; .999$ & $-1.588 ; .151$ \\
\hline & Final & $1.915 ; .092$ & $.439 ; .672$ & \\
\hline
\end{tabular}

The differences (referred to as changes in subsequent discussions) in max $\mathrm{F}_{0}$, mean $\mathrm{F}_{0}$, duration and intensity between pre-/on-/post-focus words and those words in no-focus conditions were compared. A set of repeated measures ANOVAs were performed, with focus location (neutral, initial, medial, and final) and focus condition (pre-, on- post-focus) as independent variables, and $\max \mathrm{F}_{0}$, mean $\mathrm{F}_{0}$, duration, and intensity change as dependent variables. The results are presented in Table 4. There is no significant change of max, mean $\mathrm{F}_{0}$, duration, or intensity in different focus conditions.

Table 4: Results of repeated measures ANOVAs. Degrees of freedom are land 8.

\begin{tabular}{|c|c|c|c|c|c|}
\hline \multirow[t]{2}{*}{ Sentence } & \multirow{2}{*}{ Condition } & $\operatorname{Max} F_{0}$ & $\begin{array}{c}\text { Mean } \\
F_{0}\end{array}$ & $\begin{array}{c}\text { Mean } \\
\text { duration }\end{array}$ & $\begin{array}{c}\text { Mean } \\
\text { intensity }\end{array}$ \\
\hline & & $p$ & $\mathrm{~F}$ & $\mathrm{~F}$ & $\mathrm{~F}$ \\
\hline \multirow{3}{*}{ Short } & Pre-focus & $\begin{array}{l}.265 \\
.621\end{array}$ & $\begin{array}{l}.007 \\
.937 \\
\end{array}$ & $.001 ; .980$ & $\begin{array}{l}.556 \\
.477 \\
\end{array}$ \\
\hline & On-focus & $\begin{array}{c}1.048 \\
.374\end{array}$ & $\begin{array}{c}3.176 \\
.069\end{array}$ & $.221 ; .804$ & $\begin{array}{l}2.395 \\
.123\end{array}$ \\
\hline & Post-focus & $\begin{array}{l}4.441 ; \\
.068\end{array}$ & $\begin{array}{l}.185 \\
.678\end{array}$ & $\begin{array}{c}7.181 \\
.067\end{array}$ & $\begin{array}{l}.687 ; \\
.431\end{array}$ \\
\hline \multirow{3}{*}{ Long } & Pre-focus & $\begin{array}{l}.544 \\
.482\end{array}$ & $\begin{array}{c}1.748 \\
.223\end{array}$ & $\begin{array}{l}1.236 \\
.299\end{array}$ & $\begin{array}{l}.001 ; \\
.976\end{array}$ \\
\hline & On-focus & $\begin{array}{c}1.048 ; \\
.374\end{array}$ & $\begin{array}{c}1.158 \\
.339\end{array}$ & $\begin{array}{l}1.622 \\
.228\end{array}$ & $\begin{array}{l}.159 ; \\
.854\end{array}$ \\
\hline & Post-focus & $\begin{array}{l}6.571 ; \\
.633\end{array}$ & $\begin{array}{c}4.715 \\
.062\end{array}$ & $.110 ; .749$ & $\begin{array}{l}.036 \\
.855\end{array}$ \\
\hline
\end{tabular}

Table 5: Results of repeated measures ANOVAs. Degrees of freedom are land $8 . P$ values less than .05 are in boldface.

\begin{tabular}{|c|c|c|c|c|}
\hline Factor & $\operatorname{Max} F_{0}$ & Mean $F_{0}$ & $\begin{array}{c}\text { Mean } \\
\text { duration }\end{array}$ & $\begin{array}{c}\text { Mean } \\
\text { intensity }\end{array}$ \\
\hline Condition & $\mathrm{F}$ & $\mathrm{F}$ & $p$ & $p$ \\
\hline Pre-focus & $.006 ; .939$ & $.332 ; .586$ & $\begin{array}{c}2.913 \\
.126\end{array}$ & $\begin{array}{l}.149 ; \\
.709\end{array}$ \\
\hline On-focus & $\begin{array}{c}23.099 \\
<.001\end{array}$ & $11.556 ; .001$ & $\begin{array}{c}5.057 ; \\
.020\end{array}$ & $\begin{array}{c}2.839 \\
.088\end{array}$ \\
\hline Post-focus & $6.225 ; .037$ & $.579 ; .468$ & $\begin{array}{c}3.125 ; \\
.115\end{array}$ & $\begin{array}{l}.149 \\
.709\end{array}$ \\
\hline
\end{tabular}

The comparison in max $\mathrm{F}_{0}$, mean $\mathrm{F}_{0}$, duration, and intensity change between short and long Chongqing Dialect target sentence was also conducted. A set of repeated ANOVAs are performed on the difference between short and long sentences in terms of $\max F_{0}$, mean $F_{0}$, duration and intensity in different focus regions (sentence length and focus conditions as independent variables, and max $F_{0}$, mean $F_{0}$, duration and intensity as dependent variables). The results are shown in Table 5. A significant difference between short and long sentence in max $\mathrm{F}_{0}$, mean $\mathrm{F}_{0}$ and duration change exists in on- 
focus regions $[\mathrm{F}(1,8)=23.099, p<.00 ; \mathrm{F}(1,8)=11.556, p=.001$; $\mathrm{F}(1,8)=5.057, p=.020]$. But for mean intensity, there is no interaction between sentence length and focus location.

\subsubsection{Discussion}

Generally, no interaction of focus location and focus condition is found in the changes from no focus condition to focus condition between any two factors, except the on-focus mean $\mathrm{F}_{0}$ in short sentence, which is significantly higher than the nofocus condition, showing a two-way interaction between focus location and focus condition. In addition, there is no two-way interaction of focus location and sentence length for their mean intensity in any focus areas. Thus, it seems to be difficult for Chongqing Dialect speakers to prosodically mark the presence and location of focus in either the short or long sentence.

\subsection{Perception experiment}

\subsubsection{Stimuli, participants, and listening procedure}

The stimuli in the perception experiment were taken from the production experiment. Recordings of 3 speakers were chosen - those who showed maximum, median, and minimum mean standard deviations from all $\mathrm{F}_{0}$ points across the 4 focus conditions following previous experiment design of similar research [5]. Altogether the stimuli include 2 sentences $\times 4$ foci $\times 3$ repetitions $\times 3$ speakers $=72$ sentences for every listener. 5 female and 4 male native Chongqing Dialect speakers aged 45 60 participated as listeners. Each of them listened to all the tokens. The perception experiment used ExperimentMFC in Praat and was carried out in a quiet room. The participants were asked to listen through headphones to the short sentence in the first phase, and then the long sentence in the second phase. In each phase, they decided on which of the three words or none of them was emphasized. Before the start of the experimental trials, they had some practice trials without feedback on correct focus identification until they became familiar with the procedure.

\subsubsection{Results and data analysis}

In general, focus identification rates are quite low, with the short sentence at $37.96 \%$ and the long sentence at $44.44 \%$. A set of separate t-tests are performed (with focus location and sentence length as independent variables, and correct identification rate as dependent variable), and the results are shown in Table 6. Only in initial and medial focus conditions are there significant differences in identification rate between short and long sentences $[\mathrm{t}(80)=3.592, p=.007 ; \mathrm{t}(80)=-4.472$, $p=.002]$. There is no main effect of focus on identification rate.

Table 6: Results of t-tests. Degrees of freedom are all 80. $P$ values less than .05 are in boldface.

\begin{tabular}{|c|c|c|c|}
\hline \multicolumn{3}{|c|}{ Factors } & \multirow{2}{*}{$\begin{array}{cc}\mathbf{t} & \boldsymbol{p} \\
.286 ; .782\end{array}$} \\
\hline No focus & & & \\
\hline \multirow{3}{*}{ Initial focus } & \multicolumn{2}{|c|}{ Length } & $3.592 ; .007$ \\
\hline & \multirow{2}{*}{ Focus } & Short & $-2.000 ; .081$ \\
\hline & & Long & $0.000 ; 1.000$ \\
\hline \multirow{3}{*}{ Medial focus } & \multicolumn{2}{|c|}{ Length } & $-4.472 ; .002$ \\
\hline & \multirow{2}{*}{ Focus } & Short & $2.169 ; .062$ \\
\hline & & Long & $-1.333 ; .219$ \\
\hline \multirow{3}{*}{ Final focus } & \multicolumn{2}{|c|}{ Length } & $-.894 ; .397$ \\
\hline & \multirow{2}{*}{ Focus } & Short & $1.512 ; .169$ \\
\hline & & Long & $.406 ; .695$ \\
\hline
\end{tabular}

\subsubsection{Discussion}

Compared with the identification rate of $82.3 \%$ in Beijing Mandarin with PFC [4], the overall focus identification rate of Chongqing Dialect is much lower, around half of that in Beijing Mandarin. This seems to be due to the lack of PFC, as demonstrated by the production experiment, as an effective marker of focus. Besides, the results of production experiment indicate that there is virtually no significant change of $\max \mathrm{F}_{0}$, mean $\mathrm{F}_{0}$, intensity or duration in the production of focus. In general, therefore, Chongqing Dialect seems to lack prosodic cues to effectively mark the presence and location of focus. This might be the reason why the identification rate for Chongqing Dialect is even lower than some other languages also without PFC, such as Cantonese [10]. However, on-focus mean $\mathrm{F}_{0}$ expansion is observed in short sentence, therefore a higher recognition rate at $77.78 \%$ was seen.

\section{General Discussion}

The data analysis has shown that focus in Chongqing Dialect in general does not have a significant influence on max $\mathrm{F}_{0}$, mean $\mathrm{F}_{0}$, duration and intensity. Unlike the presence of a common onfocus expansion as in other languages such as Mandarin [3] and Cantonese [10], there is virtually no sign of increase in mean $\mathrm{F}_{0}$ in the focused words in Chongqing Dialect. Only initial focus in the short sentence has a significant increase in mean $\mathrm{F}_{0}$, and the corresponding identification rate is also higher than in other conditions. Most critically, there is no evidence of PFC in the sentence of either length in the present data. The lack of PFC and significant changes in other prosodic cues such as duration and intensity has an acute effect on the perception of focus. The average recognition rate is around $40 \%$. Such a low rate suggests that there is virtually no effective prosodic means to encode focus in Chongqing Dialect.

\subsection{Difficulty of cross-language transfer of PFC through contact}

The lack of PFC shown in the present data in a dialect that is mutually intelligible to Beijing Mandarin is reminiscent of the lack of PFC in Taiwan Mandarin, which has even greater resemblance to Beijing Mandarin [4]. In the latter case, the missing PFC is apparently due to its loss when Mandarin is brought to the area, mostly through bilingualism, the most intimate form of language contact, as most of the local population continued to speak Southern Min [4]. Indeed, it has been repeatedly shown that PFC is hard to transfer from one language to another during language contact through bilingualism. There is no transfer of PFC from English to Cantonese [15], from Mandarin to Deang [8], from Mandarin to Southern Min [16], or from Mandarin to Cantonese [17]. Even between two languages both with PFC, it is difficult for this feature to transfer to each other $[16,18]$. So, the lack of PFC in Chongqing dialect could be another case of lack of transfer during historical contacts between a historical Mandarin variety with PFC and the local language in the Chongqing area. This makes it necessary to take a brief look at the language history of the area.

\subsection{The development of modern Chongqing Dialect}

Today's Chongqing dialect is based on Southwest Mandarin, with features from Ba-shu Language in Qin and Han dynasties. During the development of Chongqing dialect, four phases can be recognized. In the first phase, the language used by ancient 
$\mathrm{Ba}$ and Shu people are related to Yi and Qiang languages which are different from ancient Chinese, and are still spoken in some areas in Sichuan Province today [19]. In the second phase. the Ba-shu area was occupied by the Qin people, and a large number of them migrated into the area. In this period, Shu and Qin languages coexisted and influenced each other. Subsequently, the mixture of the Shu Language became an ancient variety of Chinese known as the Ba-shu Language in the Qin and Han dynasties [20]. By the Song dynasty, ancient Sichuan had already developed into an independent language area due to the relatively closed natural environment in the Sichuan basin [21], with huge differences between the Ba-shu Language and other languages spoken in central China [22]. In the third phase, two great migrations into the area occurred, one at the end of Yuan dynasty and the beginning of Ming dynasty, and the other at the beginning of Qing dynasty. These migrations had a profound influence on the formation of Chongqing dialect today [23]. In 1776, the native Sichuan residents accounted for $38 \%$ and migrants accounted for $62 \%$ of the total population. $60-70 \%$ of the migrants were from the Huguang areas (modern day Hubei and Hunan), others mainly from Jiangxi and Guangdong [24]. By the end of Qing Dynasty, modern Chongqing Dialect had basically formed, based on Huguang Mandarin with some features merged from the Ba-shu Language.

The final phase started during the second world war, when many national government agencies and units as well as factories moved into the area in November 1937. As a result, a large number of residents originally living in Shanghai, Jiangsu and Zhejiang Province settled there. Then at the end of 1949, the central committee of Communist Party of China stationed their Southwest bureau and military in Chongqing. Many military and government officials originally from the north moved there, bringing Northern Mandarin to Chongqing [25]. In 1955, the 'standard' Mandarin, which was phonetically similar to Beijing Mandarin, was stipulated as the official language in China, and has then been used on a mass scale across China.

\subsection{Why is there no PFC in Chongqing Dialect?}

In regard to the prosodic marking of focus, modern $\mathrm{Yi}$ and Qiang languages have been shown to have no PFC $[8,26]$. Thus due to its close link to Ying and Qiang, Shu Language in ancient Sichuan likely did not have PFC either. In contrast, the language of the Qin people is a major ancestral source of Beijing Mandarin, a well-established PFC language [3, 4], so was likely to also have PFC. The coexistence of the language of the Qin migrants and Shu language during the second phase mentioned above means that there were intense language contacts. Given the difficulty of cross-linguistic transfer of PFC reviewed in 3.1.1, PFC may have been lost in the formation of the Ba-shu dialect during this phase. What is less clear is the third phase in the development of the Chongqing dialect. The massive migration into the Sichuan area mainly came from the Huguang area. But various languages were spoken among the Huguang residents, including Xiang, Southwest Mandarin, Gan, Hakka, and Jiang-huai Mandarin [27, 28]. It has been reported that Xiang and Gan $[8,29]$ have PFC, but there is no relevant literature on precisely which of those languages were brought into Sichuan in the migrations. Yet given that modern Chongqing Dialect lacks PFC, it could be the case either the languages without PFC arrived in Sichuan, or languages originally with PFC did not transfer this feature to the descendants of Chongqing Dialect speakers. In the final phase of the Chongqing dialect, although many of the new residents came with dialects known to show PFC, including Beijing Mandarin [3], Wu dialects [30], and Shanghai Chinese [31], PFC did not emerge in Chongqing Dialect according to the present results. This is likely due not only to the small size of the new population relative to that of the local residents, but also to the non-transferability of PFC from one language/dialect to another $[4,15-18]$ as discussed earlier.

\section{Conclusions}

The production experiment in the current study has shown that the realization of prosodic focus in Chongqing Dialect does not involve on-focus expansion of $\mathrm{F}_{0}$, duration or intensity (except mean $F_{0}$ in the short sentence), and does not have post-focus compression in any of these dimensions. The perception experiment has shown that the lack of on-focus expansion and PFC in the dialect leads to a rather low identification rate of focus, at only around $40 \%$. The lack of PFC in Chongqing Dialect is despite the fact that it is a tonal language with mutual intelligibility to Beijing Mandarin where PFC is present, and with similar morphosyntactic means to mark focused constituents as in Beijing Mandarin. The current findings thus provide further evidence for the idea that the presence of PFC is independent of linguistic factors such as tone, morphosyntactic means of marking focus and even mutual intelligibility of a language with a PFC language.

The cause of the lack of PFC in Chongqing Dialect found in the current study is not yet clear, although it could be related to the historical roots of the dialect. It started in the Qin and Han dynasties as an admixture of $\mathrm{Yi}$ and Qiang, two languages known to lack PFC, with the incoming languages of the Qin people, which likely had PFC. It was then merged further with languages brought in by migrants from Huguang areas in Yuan, Ming and Qing dynasties, for which so far there is literature on the focus prosody of only some of the language varieties. Overall, it is likely that it is the heavy mixing of the languages involved that has made it difficult for PFC to be transferred into Chongqing dialect that we see today, even if some of the donor languages originally had PFC.

Given that Chongqing Dialect is a representative of Southwest Mandarin, it is possible that Southwest Mandarin as a whole does not have PFC either. The distribution of Southwest Mandarin includes all the Chinese-speaking areas in Chongqing, Sichuan, Yunnan and Guizhou provinces, as well as some cities and counties in neighbouring provinces such as Hubei, Hunan, Guangxi, Shaanxi and Gansu. There could be many variations in these areas in terms of their pronunciation and vocabulary, thus it is essential to investigate all the main clusters of Southwest Mandarin, to have a comprehensive picture of the presence of PFC in Southwest Mandarin.

\section{References}

[1] H. H. Rump and R. Collier, "Focus conditions and the prominence of pitch-accented syllables", Language and Speech, vol. 39, no. 1, pp. 1-17, 1996.

[2] A. Botinis, M. Fourakis, and B. Gawronska, "Focus identification in English, Greek and Swedish", In Proceedings of International Congress of Phonetic Sciences, San Francisco, pp. 1557-1560, 1999.

[3] Y. Xu, "Effects of tone and focus on the formation and alignment of $\mathrm{f}_{0}$ contours", Journal of Phonetics, vol. 27, no. 1, pp. 55-105, 1999.

[4] Y. Xu, S.W. Chen, and B. Wang, "Prosodic focus with and without post-focus compression: A typological divide within the 
same language family?", The Linguistic Review, vol. 29, pp. 131$147,2012$.

[5] G. Bruce, "Developing the Swedish intonation model". Lund University, Lund, 1982.

[6] A. M. Sluijter and V. J. Van Heuven, "Acoustic correlates of linguistic stress and accent in Dutch and American English", In Proceedings of International Conference on Spoken Language Processing, Philadelphia, pp. 630-633, 1996.

[7] Y. Xu and C. X. Xu, "Phonetic realization of focus in English declarative intonation", Journal of Phonetics, vol. 33, no. 2, pp. 159-197, 2005.

[8] B. Wang, L. Wang, and T. Qadir, "Prosodic Realization of Focus in Six Languages/Dialects in China", In Proceedings of International Congress of Phonetic Sciences, Hong Kong, pp. 144-147, 2011.

[9] Y. $\mathrm{Xu}$ and C. Shen, "Prosodic Focus with Post-focus Compression in Lan-Yin Mandarin", In Proceedings of Speech Prosody, Boston, pp. 340-344, 2016.

[10] W. L. Wu and Y. Xu, "Prosodic focus in Hong Kong Cantonese without post-focus compression", In Proceedings of Speech Prosody, Chicago, pp. 1-4, 2010.

[11] Z. H. Liu, Van de Velde, and A. J. Chen, "Prosodic focus marking in Dali Mandarin", In Proceedings of International Symposium on Tonal Aspects of Languages, Buffalo, pp. 103-106, 2016.

[12] W. E. Cooper, S. J. Eady, and P. R. Mueller, "Acoustical aspects of contrastive stress in question-answer contexts", The Journal of the Acoustical Society of America, vol. 77, no. 6, pp. 2142-2156, 1985.

[13] Y. Xu, "ProsodyPro - A tool for large-scale systematic prosody analysis", In Proceedings of Tools and Resources for the Analysis of Speech Prosody, Aix-en-Provence, pp. 7-10, 2013.

[14] P. Boersma, "Praat, a system for doing phonetics by computer", Glot international, 2002.

[15] W. L. Wu and Chung, L. Post-focus Compression in EnglishCantonese Bilingual Speakers. In Proceedings of International Congress of Phonetic Sciences, Hong Kong, pp. 148-151, 2011.

[16] Y. Chen, Y. Xu, and S. Guion-Anderson, "Prosodic realization of focus in bilingual production of Southern Min and Mandarin”, Phonetica, vol. 71, no. 4, pp. 249-270, 2014.

[17] K. L. K. Fung, "Prosodic Focus in Cantonese and Mandarin by native Hong Kong Cantonese speakers", University College London, London, 2010.

[18] Y. Chen, "Post-focus compression in English by Mandarin learners". In Proceedings of International Congress of Phonetic Sciences, Glasgow, 2015.

[19] Q.M Wang and J. Zhao, "Three Subjects of Research on Shu Dialect in Chinese Ancient and Middle Ancient Times", Journal of Southwest Jiaotong University (Social Sciences), vol. 9, no. 6, pp. 27-31, 2008.

[20] Q. M. Wang, "The Ancient Shu Phonetic Development Theory", Journal of Chengdu Technological University, vol. 1, pp. 69-73, 2014.

[21] Z.H. Zhou and R.J. You, "Dialect and Chinese Culture", Journal of Fudan University: social sciences, vol. 3, pp. 232-237, 1985.

[22] X.N. Liu, "Sichuan dialect in song dynasty from historical documents", Journal of Sichuan University: philosophy and social sciences, vol. 2, pp. 36-45, 2008.

[23] Cao, S. J. Migration History of China, Vol. 5. Fuzhou, China: Fujian People's Publishing House, 1997.

[24] J.X. Zhou, "New Thesis on Immigrating in the Ming Dynasty and Evolving of the Sichuan Dialects", Studies in Languages and Linguistics, vol. 1, pp. 52-59, 2013.

[25] Q.Y. Luo, "Immigration and the Formation of Modern Chongqing Dialect", Journal of Chongqing University of Arts and Science, vol. 4, pp. 6-10, 2014.

[26] X. Zhang and B. Wang, "Production and perception of focus in L2 Mandarin of Qiang speakers", In Proceedings of International Symposium on Chinese Spoken Language Processing, Tianjin, 2016.

[27] J.G. Peng, and Z.R. Peng, "Research on the History of Hunan Dialect", Social Sciences in Hunan, vol. 1, pp.156-162, 2008

[28] F.Y. Xing and G.S. Wang, "Research on Hubei dialect", Chinese Linguistics, vol. 3, pp. 31-32, 2015.
[29] X. Yang, "Prosodic Realization of Focus in One Xiang Dialect of Chinese", University College London, London, 2012.

[30] B. Wang, Y. Zhang, Y. Xu, and H. Ding, "Prosodic focus in three northern Wu dialects: Wuxi, Suzhou and Ningbo", In Proceeding of 8th Experimental Linguistics, Heraklion, pp. 117-120, 2017.

[31] E. Selkirk, and T. Shen, "Prosodic domains in Shanghai Chinese", in The Phonology-Syntax Connection, S. Inkelas and Z. Draga, Eds. Chicago, IL, USA: University of Chicago Press. 1990, pp. 313-337. 